\title{
Raised Adolescent Body Mass Index Predicts the Development of Adiposity and a Central Distribution of Body Fat in Adulthood: A Longitudinal Study
}

\author{
Angela M. Craigie ${ }^{a}$ John N.S. Matthews ${ }^{b}$ Andrew J. Rugg-Gunn ${ }^{a} \quad$ Amelia A. Lake $^{a}$ \\ John C. Mathers ${ }^{c}$ Ashley J. Adamson ${ }^{a}$ \\ ${ }^{a}$ Institute of Health and Society, Human Nutrition Research Centre, \\ ${ }^{b}$ School of Mathematics and Statistics, \\ ${ }^{\mathrm{c}}$ Institute for Ageing and Health, Human Nutrition Research Centre, Newcastle University, Newcastle upon Tyne, UK
}

\section{Key Words}

Body mass index - Obesity - Waist circumference .

Adolescence · Tracking

\section{Summary}

Objective: To test the hypothesis that adolescent body mass index (BMI) tracks into adulthood and can be used as a predictor of obesity and/or central adiposity in adulthood. Method: A prospective cohort study following up 111 female and 84 male subjects who participated in dietary and anthropometric surveys when aged 12 years (in 1979-1981) and 33 years (in 2000-2001). At both timepoints, height and weight were measured and BMI calculated. At 33 years, waist circumference (WC) and hip circumference were also measured and waist-to-hip ratio (WHR) calculated. Results: In the male and female participants, BMI at 12 years was associated significantly with $\mathrm{BMI}$ at 33 years $(R=0.58$ and 0.53 , respectively, both $p<0.01)$ and $W C$ at 33 years $(R=0.58$ and 0.53 , both $p<$ $0.01)$. The probability of being an obese adult increased with rising adolescent $\mathrm{BMI}$ : normal weight male $(\mathrm{BMI}<$ $20.89 \mathrm{~kg} / \mathrm{m}^{2}$ ) and female subjects (BMI $<21.20 \mathrm{~kg} / \mathrm{m}^{2}$ ) at 12 years had a $20 \%$ and a $7 \%$ chance of being obese at 33 years, respectively; the probabilities for obese male $\left(\mathrm{BMI} \geq 25.58 \mathrm{~kg} / \mathrm{m}^{2}\right)$ and female subjects $\left(\mathrm{BMI} \geq 26.05 \mathrm{~kg} / \mathrm{m}^{2}\right)$ were 83 and $64 \%$. The corresponding probability of becoming centrally obese (measured by WC) increased from 17 and $16 \%$ in male and female subjects of a normal weight to 58 and $59 \%$ in those being obese. Conclusions: Adolescent $\mathrm{BMI}$ is a good predictor of adult $\mathrm{BMI}$ and WC and the likelihood of becoming obese and/or centrally obese in adulthood.

\section{Introduction}

Obesity is the accumulation of excess adipose tissue and is most commonly classified as a body mass index (BMI) $\geq 30$ $\mathrm{kg} / \mathrm{m}^{2}$. Its prevalence is increasing at an alarming rate throughout the world, and in England it has tripled over the last 2 decades $[1,2]$. If current trends continue, around a third of the adults and a fifth of the children in England will be obese by 2010 [3].

The distribution of body fat is also important. Accumulation of fat intra-abdominally increases the risk of type 2 diabetes, hypertension, and hyperlipidaemia and may be a greater cardiovascular disease risk factor than raised BMI per se [4]. Whilst waist circumference (WC) alone is considered to be the best anthropometric predictor of visceral fat [4] and is positively associated with an increased risk of several types of cancer, most convincingly colorectal cancer [5], the ratio of waist circumference to hip circumference (WHR) has been shown to be a strong predictor of overall mortality, particularly in women [6].

Adult obesity is notoriously difficult to treat [7], so intervention programmes are increasingly focusing on early preventive measures. Screening is one option but relies on the ability to identify at an early age the individuals 'at risk' of becoming adults who are obese and/or have high levels of central adiposity. Adiposity in childhood may be one indicator of 'risk'. While it is recommended that BMI be used to estimate general adiposity in children, the use of WC is not advised [8]. We aimed to test the hypothesis that adult BMI, WC, and WHR are associated with BMI in early adolescence and to quantify any such association.

\begin{tabular}{ll}
\hline KARGER & ( 2009 S. Karger GmbH, Freiburg \\
$\begin{array}{l}\text { Fax }+497614520714 \\
\text { Information@Karger.de } \\
\text { www.karger.com }\end{array}$ & $\begin{array}{l}\text { Accessible online at: } \\
\text { www.karger.com/ofa }\end{array}$ \\
&
\end{tabular}




\section{Participants and Methods}

\section{Participants}

The potential participants of the ASH30 Study were the 405 12-yearolds who participated in a dietary and anthropometric survey carried out between 1979 and 1981 in south Northumberland, North East England [9]. These participants were 33 years old in 2000-2001, and all who were traced and agreed to participate were included except those known to be pregnant at the time of measurement.

\section{Anthropometric Measurements}

Height and weight were measured at both time-points and WC and hip circumference (HC) at 33 years old only. All measurements were taken in light indoor clothing. At 12 years, height was measured to the nearest $0.5 \mathrm{~cm}$ using a sliding headpiece, and weight was measured to the nearest $0.5 \mathrm{~kg}$ using a Seca scale [9]. At 33 years, height was measured to the nearest $0.1 \mathrm{~cm}$ using a portable Soehnle electronic vertical stadiometre and weight was measured to the nearest $0.1 \mathrm{~kg}$ using Tanita digital scales. BMI was calculated at both time-points. International definitions were used to classify individuals according to their BMI at 12 and 33 years into 'normal weight', 'overweight', or 'obese' [10,11]. At 12 years old, the definitions for the closest age category (11.5 years) for boys and girls defined overweight as a BMI at or above 20.89 and $21.20 \mathrm{~kg} / \mathrm{m}^{2}$, and obesity as a BMI at or above 25.58 and $26.05 \mathrm{~kg} / \mathrm{m}^{2}$, respectively [11]. At 33 years old, overweight was defined as a BMI $\geq 25.0$ and $<30.0 \mathrm{~kg} / \mathrm{m}^{2}$ and obesity as a $\mathrm{BMI} \geq 30.0 \mathrm{~kg} / \mathrm{m}^{2}$ [10]. At 33 years only, WC and $\mathrm{HC}$ were measured to the nearest $0.1 \mathrm{~cm}$ [12]. Subjects were classified as 'centrally obese' according to the World Health Organisation's criteria for WC (women $\geq 88$ $\mathrm{cm}$, men $\geq 102 \mathrm{~cm}$ ) and WHR (women $\geq 0.85$, men $\geq 1.00$ ) [10].

\section{Statistical Methods}

Factors influencing whether or not an individual (out of the original 405 subjects) was available for measurement at age 33 were assessed using summary statistics and logistic regression. For those who participated in both surveys, the BMI data at 12 and 33 years and the WC data at 33 years followed log-normal distributions; therefore, all analyses on these data were performed after taking the logarithm to base 10. Associations between measurements at ages 12 and 33 were assessed using correlation and regression. The latter assumes normally distributed residuals, and this assumption was checked using probability plots. In addition, the difference in regression parameters between male and female subjects was assessed using appropriate tests of interaction. The estimated regression equation was used to calculate the probability of being overweight or obese as functions of BMI at 12 years. The chances of being obese, overweight, or normal weight at ages 33 or 12 given a particular status at the other age were calculated using the joint normality of the logged values.

\section{Ethical Approval}

Ethical approval was obtained from the UK Multi-Centre Research Ethics Committee and from fifty Local Research Ethics Committees.

\section{Results}

Subjects

Of the 405 original participants [9], 195 participated fully in the 2000-2001 survey (111 female and 84 male): a further 7 agreed to participate but were pregnant at the time of measurement. Of the remaining 203 subjects, 96 either declined to participate or failed to complete the study. The locations of a further 18 were traced but they could not be contacted (e.g. in the armed forces). The remaining 89 could not be traced.

The age and anthropometric measurements recorded at each time-point are presented in table 1. All subjects were from the same ethnic group: Caucasian. At baseline, both male and female participants were on average aged 11.6 years and were not significantly different in terms of height, weight, or BMI. $10 \%(n=8)$ of the boys and $9 \%(n=10)$ of the girls were overweight whilst $4 \%(n=3)$ of the boys and $1 \%(n=1)$ of the girls were obese. At follow-up, male subjects were on average aged 32.6 years and female subjects 32.5 years. Male subjects were significantly taller, heavier, and had a higher BMI (all $\mathrm{p}<0.01)$ than female subjects. This was reflected in the proportions overweight and obese: $48 \%(n=40)$ of the men and $33 \%$ $(n=37)$ of the women were overweight, and $26 \%(n=22)$ of the men and $15 \%(n=17)$ of the women were obese.

\section{Association between BMI at 12 Years and Adiposity at 33 Years}

\section{Obesity and Overweight}

The BMI at 33 years old was strongly associated with the BMI at 12 years old, the correlations being very similar for male and female participants (both $\mathrm{p}<0.001$ ) (table 2). The slope of the regression of $\log _{10}$ BMI at age 33 on $\log _{10}$ BMI at age 12 was similar in male and female subjects (test for interaction $\mathrm{p}=0.55)$. The data can thus be described most succinctly by a regression of $\log _{10} \mathrm{BMI}$ at age 33 on $\log _{10} \mathrm{BMI}$ at age 12 , with different intercepts for male and female subjects (fig. 1). For any given BMI at age 12, the geometric mean BMI at age 33 was $7 \%$ smaller for female than for male subjects (95\% confidence interval (CI) 4-11\%).
Table 1. Anthropometric measurements recorded at 12 and 33 years of age

\begin{tabular}{|c|c|c|c|c|}
\hline & \multicolumn{2}{|c|}{ Mean at 12 years old $(95 \% \mathrm{CI})$} & \multicolumn{2}{|c|}{ Mean at 33 years old $(95 \% \mathrm{CI})$} \\
\hline & male $(\mathrm{n}=84)$ & female $(n=111)$ & male $(\mathrm{n}=84)$ & female $(\mathrm{n}=111)$ \\
\hline Age, years & $11.6(11.5-11.6)$ & $11.6(11.5-11.6)$ & $32.6(32.5-32.6)$ & $32.5(32.5-32.6)$ \\
\hline Height, m & 1.47 (1.46-1.49) & $1.49(1.47-1.50)$ & $1.78(1.77-1.79)$ & $1.63(1.62-1.65)$ \\
\hline Weight, kg & $39.2(37.6-40.9)$ & $39.5(38.0-41.0)$ & $86.9(84.2-89.6)$ & $67.2(64.8-69.6)$ \\
\hline $\mathrm{BMI}, \mathrm{kg} / \mathrm{m}^{2 \mathrm{a}}$ & $18.2(17.6-18.7)$ & $17.9(17.4-18.3)$ & $27.5(26.7-28.3)$ & $25.2(24.4-26.0)$ \\
\hline $\mathrm{WC}, \mathrm{cm}^{\mathrm{a}}$ & NM & NM & $92.9(90.8-95.1)$ & $79.5(77.6-81.5)$ \\
\hline $\mathrm{HC}, \mathrm{cm}$ & NM & NM & $104.3(102.9-105.7)$ & $102.0(100.1-103.9)$ \\
\hline WHR & NM & NM & $0.89(0.88-0.90)$ & $0.79(0.77-0.80)$ \\
\hline
\end{tabular}

${ }^{\mathrm{a}}$ Geometric means.

$\mathrm{NM}=$ Not measured. 
The probability that an individual at age 33 was obese or overweight, but not obese, depended on the sex of the individual and on their BMI at age 12 (table 3). Female participants were less likely than male participants to become obese regardless of the BMI at 12 years old, and the probability of becoming obese increased with rising BMI at 12 years old. For example, for an individual with a normal BMI [11] at age 12, the probability of being obese at age 33 was $20 \%$ for men but only $7 \%$ for women. The corresponding probabilities for an individual who was overweight but not obese [11] at age 12 was $56 \%$ for a man and $32 \%$ for a woman, and for an individual who was obese at age 12 , it was $83 \%$ in men and $64 \%$ in

Table 2. The association between $\log _{10}$ BMI at 12 years old and $\log _{10}$ BMI, WC, and WHR at 33 years old

\begin{tabular}{lll}
\hline & \multicolumn{2}{l}{ Pearson correlation coefficient } \\
\cline { 2 - 3 } & male & female \\
\hline $\log _{10}$ BMI at age 33 & $0.58^{*}$ & $0.53^{*}$ \\
WC at age 33 & $0.49^{*}$ & $0.34^{*}$ \\
WHR at age 33 & $0.36^{*}$ & 0.04 \\
\hline
\end{tabular}

$* \mathrm{p}<0.01$ women. The way the probability of being obese (or overweight but not obese) at age 33 varies with the BMI at age 12 is illustrated in figure 2. Conversely, the probability of those who were obese at 33 years old of having been normal weight at 12 years old was $65 \%$ for male and $77 \%$ for female subjects.

\section{Central Obesity}

The $\log _{10}$ WC at 33 years old was clearly associated with the $\log _{10}$ BMI at 12 years old, with similar correlations for both sexes (p $<0.001$ for both) (table 2). The slopes of the regression of the $\log _{10}$ WC on the $\log _{10}$ BMI at age 12 were also similar for both male and female subjects: test for interaction, $\mathrm{p}=0.59$. Thus, the data are described using a regression of the $\log _{10} \mathrm{WC}$ on the $\log _{10}$ BMI at 12 years, with separate intercepts for male and female participants (fig. 3). For any BMI at age 12, the geometric mean WC was $14 \%$ smaller for women than for men (95\% CI, $11-17 \%)$, coinciding with the $14 \%$ difference in the thresholds used to define central obesity in men and women (88 vs. 102 $\mathrm{cm})$. Thus, the probability of becoming centrally obese was not different for males and females (table 3). In contrast, the probability of becoming centrally obese increased with the BMI at 12 years from 17 and $16 \%$ if of a normal weight to 58 and $59 \%$ if obese at 12 years old for boys and girls, respectively.
Table 3. The probabilities of being obese or overweight at 33 years old, given the corresponding status at age 12 years old
Fig. 1. Regression of $\log _{10} \mathrm{BMI}$ at 33 years old on $\log _{10}$ BMI at 12 years old.

\begin{tabular}{|c|c|c|c|c|c|c|c|c|}
\hline \multirow{3}{*}{$\begin{array}{l}\text { BMI status at } 12 \\
\text { years }^{\mathrm{a}}\end{array}$} & \multicolumn{8}{|c|}{ Status at age 33 years } \\
\hline & \multicolumn{2}{|c|}{$\begin{array}{l}\text { Normal weight } \\
(\mathrm{BMI}<25)\end{array}$} & \multicolumn{2}{|c|}{$\begin{array}{l}\text { Overweight, not obese } \\
(\mathrm{BMI}>25 \text { and }<30)\end{array}$} & \multicolumn{2}{|c|}{$\begin{array}{l}\text { Obese } \\
(\mathrm{BMI} \geq 30)\end{array}$} & \multicolumn{2}{|c|}{$\begin{array}{l}\text { Centrally obese } \\
\text { (determined by WC) }\end{array}$} \\
\hline & male & female & male & female & male & female & male & female \\
\hline Normal & 0.27 & 0.52 & 0.53 & 0.41 & 0.20 & 0.07 & 0.17 & 0.16 \\
\hline $\begin{array}{l}\text { Overweight, } \\
\text { not obese }\end{array}$ & 0.04 & 0.13 & 0.40 & 0.55 & 0.56 & 0.32 & 0.38 & 0.38 \\
\hline Obese & 0.01 & 0.02 & 0.16 & 0.34 & 0.83 & 0.64 & 0.58 & 0.59 \\
\hline
\end{tabular}

${ }^{\mathrm{a} B M I}$ status at 12 years old (BMI range, $\mathrm{kg} / \mathrm{m}^{2}$ ) [11]. Normal weight (boys $<20.89$, girls $<21.20$ ); overweight (boys 20.89-25.58, girls 21.20-26.05); obese (boys $>25.58$, girls $>26.05$ ).

${ }^{b}$ Male WC $>102 \mathrm{~cm}$, female $\mathrm{WC}>88 \mathrm{~cm}$. 
Fig. 2. The probability of being obese or overweight at 33 years old based on BMI and sex at 12 years old.

Fig. 3. Regression of $\log _{10} \mathrm{WC}$ at 33 years old on $\log _{10}$ BMI at 12 years old.

Fig. 4. Regression of $\log _{10} \mathrm{WHR}$ at 33 years old on $\log _{10}$ BMI at 12 years old.
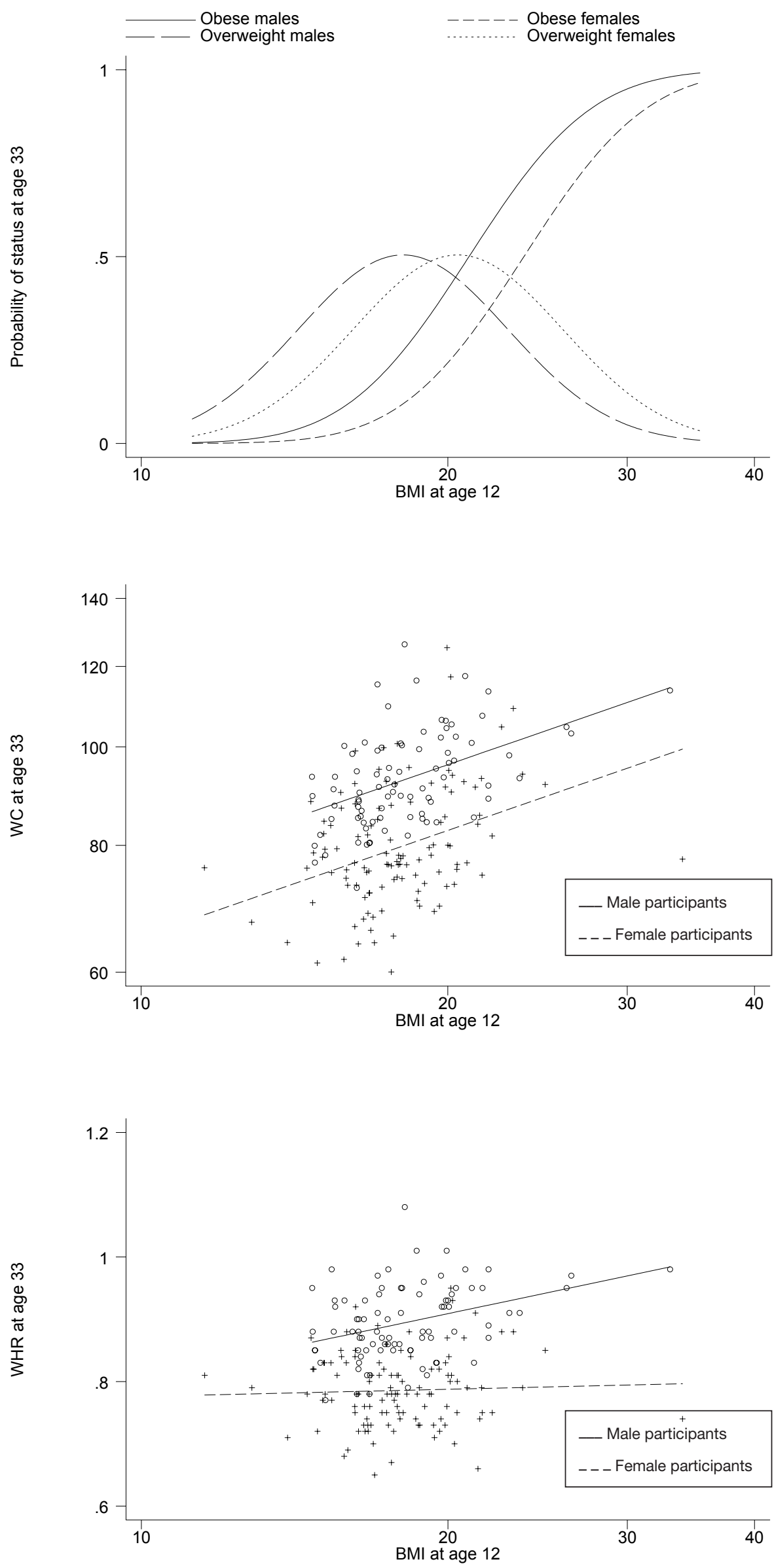
Table 4. Comparison of sex, social group, and BMI at 12 years old by participation status at 33 years old

Table 5. Odds of being a participant at age 33 based on BMI, sex, and social group at age 12

\begin{tabular}{|c|c|c|c|c|c|c|}
\hline & \multirow{2}{*}{$\begin{array}{l}\text { BMI, } \\
\text { geometric means }\end{array}$} & \multirow{2}{*}{$\begin{array}{l}\text { Sex, } \\
\% \text { female }\end{array}$} & \multicolumn{4}{|c|}{ Social group $(\%)^{\mathrm{a}}$} \\
\hline & & & I & II & III & IV \\
\hline Participants & 18.01 & 58.4 & 26 & 46 & 24 & 5 \\
\hline Non-participants & 18.14 & 46.3 & 16 & 39 & 34 & 10 \\
\hline $\begin{array}{l}\text { Difference between participants } \\
\text { and non-participants }\end{array}$ & $0.99(0.97-1.02)^{\dagger}$ & $12.0(2.5-22)$ & & & & \\
\hline p-value & 0.58 & 0.015 & & & & \\
\hline
\end{tabular}

aSocial group in 1980 derived from 1970 classification of the Registrar General. I = Classes $1+2$ (highest); $\mathrm{II}=$ class $3 ; \mathrm{III}=$ classes $4+5$ (lowest); IV = unclassified.

'Expressed as a ratio due to the analysis being carried out on log transformed data.

\begin{tabular}{llll}
\hline & $\begin{array}{l}\text { Odds ratio }{ }^{\mathrm{a}} \text { of being a participant } \\
\text { in 2000-2001 }\end{array}$ & 95\% CI & p value \\
\hline BMI & 0.98 & $0.91-1.06$ & 0.63 \\
Sex & 1.82 (females relative to males) & $1.21-2.74$ & 0.004 \\
Social group II & 0.71 (relative to social group I) & $0.41-1.21$ & \\
Social group III & 0.40 (relative to social group I) & $0.22-0.72$ & 0.002 \\
Social group IV & 0.27 (relative to social group I) & $0.11-0.65$ & \\
\hline
\end{tabular}

${ }^{a}$ Odds ratio of being a participant comparing subjects with unit difference in BMI.
The association between the $\log _{10}$ BMI at age 12 and WHR at age 33 was different for both sexes (test for interaction: $p$ $=0.027$ ) (fig. 4). There was a significant $(\mathrm{p}<0.01)$ association with the $\log _{10} \mathrm{BMI}$ at age 12 for men but no association was apparent for women (table 2, fig. 4).

\section{Participants versus Non-Participants}

Of the 405 participants surveyed in 1979-1981, just under half $(\mathrm{n}=195)$ participated in the 2000-2001 survey. To assess how representative the latter were of the original cohort, the 2000-2001 participants and non-participants were compared with respect to the key variables in the first survey (table 4). Logistic regression showed that the BMI was similar for both participants and non-participants $(\mathrm{p}=0.63)$ but the 2000-2001 participants were more likely to be female $(p=0.004)$ and less likely to be from lower and unclassified social groups (III and IV) $(\mathrm{p}=0.002)$ (table 5). Analysis of variance was used to assess the effect of sex and social group (as defined in 1980) on the BMI in 2000-2001 among participants, and we found that social group had no significant $(\mathrm{p}=0.66)$ effect on the BMI in 2000-2001, but the effect of sex was highly significant ( $\mathrm{p}=$ 0.0002 , ratio of geometric means 1.09 , 95\% CI 1.04-1.14).

\section{Discussion}

The BMI at 12 years old was strongly associated with the adult BMI and WC and, therefore, with adult obesity and central obesity (as defined by WC). Hence, those classified as overweight or obese [11] at 12 years old had a higher risk of becoming adults who were obese or centrally obese, based on WC [10], than those of normal weight. Adolescent BMI was a poorer predictor of adult WHR, with no discernible association in female subjects.

Our finding that BMI in adolescence predicts BMI in adulthood confirms findings from other studies. For example, a review of studies published between 1985 and 1996 [13] found positive correlations between 13-14 and 25-36 years of age for BMI and other indices of adiposity based on weight and height. These varied from $0.46-0.91$ for male and $0.60-0.78$ for female subjects, with weaker correlations between younger ages and adulthood. All 12 studies reviewed found that fatter children were more likely to be obese later in life than their leaner counterparts. Several studies published since 1996 have also supported these findings [14-24]. Indeed, there is evidence that childhood or adolescent BMI predicts adult indicators of cardiovascular risk, such as carotid intima-media thickness, a relationship thought to be explained largely by the tracking of BMI [22-23, 25].

The age at which the participants of this study initially took part may be of significance given that they were likely to be around the age of their pubertal growth spurt, particularly the girls. The prediction of adiposity in adulthood has been related specifically to adiposity measurements at critical periods such as birth, 1 year of age, or the age of adiposity rebound, but most strongly around puberty $[18,26]$. A possible limitation of this study is the lack of data on pubertal stage of the participants. The methods and setting used precluded any such assessment.

The mechanism responsible for the very high association between BMI in adolescence and adulthood is not known, but it could reflect a persistence of behaviours that influence energy intake and/or expenditure. There is some evidence to 
support this for both dietary intake [27-30] and physical activity [31-33], though the level of tracking for each of these is not quite as strong. Alternatively, it is possible that there may be a genetic propensity for adiposity, however, there remains uncertainty regarding the magnitude of the contribution of genes to obesity; estimates range from 5 to $90 \%$ [34]. Likewise, twin studies have shown that genetics is a determinant of WHR and to a greater extent of WC [35].

In contrast to BMI, despite the risks of an intra-abdominal accumulation of body fat [4-5], few studies have considered the predictive value of the BMI in adolescence on central adiposity in adulthood, and this study is unique in providing evidence of the relationship with WC. Casey et al. [36] found that both WHR and BMI during adolescence, particularly in the year of peak height velocity, were good predictors of WHR at 30 years $(\mathrm{R}>0.50)$ in both sexes. Rolland-Cachera et al. [37] also found that BMI was one of the best childhood predictors of central obesity based on trunk/extremity skinfold ratios at 21 years of age. Van Lenthe et al. [38] reported that a central pattern of body fat at 13 years of age, determined as three trunk/extremity skinfold ratios, was associated significantly with those measurements at 29 years of age $(\mathrm{R} \sim 0.55)$. More recently, Eisenmann et al. [22] reported a relatively strong correlation between $\mathrm{WC}$ at 16 and 27 years $(\mathrm{R}=0.79)$, providing some support for the measurement of adolescent $\mathrm{WC}$ as an indicator of central adiposity in adulthood.

In children, $\mathrm{BMI}$ is reported to be the best single measure of adiposity [13] and the use of $\mathrm{WC}$ for this purpose is not recommended [8]. In adults, the World Health Organisation's cut-offs for BMI, WHR, and WC are all useful in identifying individuals with increased cardiovascular $[10,39]$ and bowel cancer [5] risk. Despite the strength of this evidence, there has been some dispute about which anthropometric measurement is the most appropriate indicator of visceral fat and a predictor of disease risk [22]. WC has been recommended due to its simplicity and because it is a better indicator of visceral fat than WHR $[4,40]$. The WHR cut-offs used in this study were those recommended by the World Health Organisation [10] and are higher than some others proposed which could explain the relative weakness of the prediction of adult central adiposity by adolescent BMI. WHR is known to be a good predictor of mortality and morbidity but it is more difficult to interpret biologically since the ratio is influenced by both muscle and fat distribution [40]. For this reason, WC is often the preferred surrogate for central adiposity.

It is important to acknowledge the limitations of this study. The generalisability of the findings is restricted by the limited ethnic diversity of the sample studied, which is a consequence of the largely Caucasian population resident in the study area in 1980. The analysis presented in table 3 is also reliant on the measures of adiposity studied in 1980 and 2000 having bivariate normal distributions. Furthermore, following up a group over a 20-year time scale gives potential for recruitment bias. To quantify this aspect, we compared the 1980 characteristics of the participants in the 2000-2001 survey (48\% of total) with the non-participants of the later survey. Those who were male or from lower and unclassified social groups in 1980 were less likely to take part. The potential impact of these factors on the BMI in 2000 was analysed and whilst there was no association with social class, being male was a significant predictor of BMI. Thus, to control for this, all our analyses were carried out for male and female participants separately.

\section{Conclusions}

This study provides good evidence that 12-year-olds classified as overweight or obese, according to their BMI, had more than a 4 times higher risk of becoming obese or centrally obese by 33 years of age than their normal weight counterparts. These findings provide support for the use of BMI and the international definitions of overweight and obesity [11] as relatively cheap, easy-to-administer, and non-invasive screening tools to identify young adolescents most at risk of adult obesity. Clearly, screening is of value only if appropriate and effective treatment strategies are available for young people. Whilst such guidance is available from NICE [8], there is still a need for further research in this area. Strategies for the treatment of overweight and obesity in adolescence should be implemented sensitively given the potential short- and longterm psychological risks of labelling vulnerable young people as 'overweight' or 'obese'.

It is also important to note that the majority of obese or centrally obese adults were normal weight adolescents. This highlights the need for effective measures to prevent the development of obesity not only in childhood but also throughout adolescence and early adulthood. As with the treatment of early obesity [41], there is a lack of evidence regarding preventive strategies [42-43]. Future research is therefore required to establish effective prevention and treatment strategies, with consideration given to studies at the societal rather than just the individual level [44].

\section{Acknowledgements}

The authors would like to thank the Wellcome Trust for funding this study (Ref: 057995/Z/99/Z); Charlotte Wood and Megan Gibbons for their assistance with the ASH30 Study data collection; Dr Alan Hacket for the collection of the 1980 data; the Office for National Statistics for their coding of the 2000-2001 social class data; as well as the participants for their contribution to both studies.

\section{Disclosure}

Amelia A. Lake and Ashley J. Adamson are both funded by the National Institute for Health Research Personal Awards. The views expressed in this publication are those of the authors and not necessarily those of the NHS, NIHR, or Department of Health. 


\section{References}

1 Department of Health: Obesity, defusing a health time bomb. Health check: on the state of the public health. Annual report of the Chief Medical Officer. London, Department of Health Publications, 2002, pp 37-46.

2 Lean ME: Pathophysiology of obesity. Proc Nutr Soc 2000;59:331-336.

3 Joint Health Surveys Unit for the Department of Health: Forecasting Obesity to 2010. London, Department of Health Publications, 2006.

$\checkmark 4$ Han TS, Sattar N, Lean M: ABC of obesity. Assessment of obesity and its clinical implications. BMJ 2006;333:695-698.

5 World Cancer Research Fund/American Institute for Cancer Research: Food, Nutrition, Physical Activity and the Prevention of Cancer: a Global Perspective. Washington, DC, WCRF and AICR, 2007.

6 Reis JP, Macera CA, Araneta MR, Lindsay SP, Marshall SJ, Wingard DL: Comparison of overall obesity and body fat distribution in predicting risk of mortality. Obesity (Sliver Spring) 2009; DOI: 10.1038/oby.2008.664.

7 Mulvihill C, Quigley R: The Management of Obesity and Overweight: an Analysis of Reviews of Diet, Physical Activity and Behavioural Approaches. London, HDA, 2003.

8 National Institute for Clinical Excellence: Obesity: the prevalence, identification, assessment and management of overweight and obesity in adults and children, 2006. http://www.nice.org.uk/CG43.

$\checkmark$ Hackett AF, Rugg-Gunn AJ, Appleton DR, Eastoe JE, Jenkins GN: A 2-year longitudinal nutritional survey of 405 Northumberland children initially aged 11.5 years. Br J Nutr 1984;51:67-75.

10 World Health Organisation: Obesity, preventing and managing the global epidemic: report of a WHO Consultation on Obesity. Geneva, World Health Organisation, 1998.

11 Cole TJ, Bellizzi MC, Flegal KM, Dietz WH: Establishing a standard definition for child overweight and obesity worldwide: international survey. BMJ 2000;320:1240-1243.

12 Han TS, Lean ME: Self-reported waist circumference compared with the 'Waist Watcher' tapemeasure to identify individuals at increased health risk through intra-abdominal fat accumulation. $\mathrm{Br}$ J Nutr 1998;80:81-88.

13 Power C, Lake JK, Cole TJ: Measurement and longterm health risks of child and adolescent fatness. Int J Obes Relat Metab Disord 1997;21:507-526.

14 Srinivasan SR, Bao W, Wattigney WA, Berenson GS: Adolescent overweight is associated with adult overweight and related multiple cardiovascular risk factors: the Bogalusa Heart Study. Metabolism 1996; 45:235-240.

15 Valdez R, Greenlund KJ, Wattigney WA, Bao W, Berenson GS: Use of weight-for-height indices in children to predict adult overweight: the Bogalusa Heart Study. Int J Obes Relat Metab Disord 1996;20: 715-721.

16 Guo SS, Chumlea WC: Tracking of body mass index in children in relation to overweight in adulthood. Am J Clin Nutr 1999;70:145S-148S.
17 Lambrechtsen J, Rasmussen F, Hansen HS, Jacobsen IA: Tracking and factors predicting rising in 'tracking quartile' in blood pressure from childhood to adulthood: Odense Schoolchild Study. J Hum Hypertens 1999;13:385-391.

18 Laitinen J, Power C, Jarvelin M: Family social class, maternal body mass index, childhood body mass index, and age at menarche as predictors of adult obesity. Am J Clin Nutr 2001;74:287-294.

19 Williams S: Overweight at age 21: the association with body mass index in childhood and adolescence and parents' body mass index. A cohort study of New Zealanders born in 1972-1973. Int J Obes Relat Metab Disord 2001;25:158-163.

20 Magarey AM, Daniels LA, Boulton TJ, Cockington RA: Predicting obesity in early adulthood from childhood and parental obesity. Int J Obes Relat Metab Disord 2003;27:505-513.

21 Trudeau F, Shephard RJ, Bouchard S, Laurencelle L: BMI in the Trois-Rivieres study. Child-adult and child-parent relationships. Am J Hum Biol 2003;15: 187-191.

22 Eisenmann JC, Welk GJ, Wickel EE, Blair SN; Aerobics Center Longitudinal Study: Stability of variables associated with the metabolic syndrome from adolescence to adulthood: the Aerobics Center Longitudinal Study. Am J Hum Biol 2004;16: 690-696.

23 Raitakari OT, Juonala M, Viikari JS: Obesity in childhood and vascular changes in adulthood: insights into the Cardiovascular Risk in Young Finns Study. Int J Obes (Lond) 2005;29(suppl 2):101-104.

24 Wang LY, Chyen D, Lee S, Lowry R: The association between body mass index in adolescence and obesity in adulthood. J Adolesc Health 2008;42: 512-518.

25 Oren A, Vos LE, Uiterwaal CS, Gorissen WH, Grobbee DE, Bots ML: Change in body mass index from adolescence to young adulthood and increased carotid intima-media thickness at 28 years of age: the Atherosclerosis Risk in Young Adults study. Int J Obes Relat Metab Disord 2003;27: 1383-1390.

26 Guo SS, Huang C, Maynard LM, Demerath E, Towne B, Chumlea WC, Siervogel RM: Body mass index during childhood, adolescence and young adulthood in relation to adult overweight and adiposity: the Fels Longitudinal Study. Int J Obes Relat Metab Disord 2000;24:1628-1635.

27 Craigie AM, Lake AA, Wood C, Gibbons M, Webster S, Adamson AJ, Rugg-Gunn AJ, Mathers JC: The stability of nutrient intake between adolescence and adulthood: a 21-year follow-up. Proc Nutr Soc 2002;61:105.

28 Lake AA, Mathers JC, Rugg-Gunn AJ, Adamson AJ: Longitudinal change in food habits between adolescence (11-12 years) and adulthood (32-33 years): the ASH30 Study. J Public Health (Oxf) 2006;28: 10-16.

29 Bertheke Post B, de Vente W, Kemper HC, Twisk JW: Longitudinal trends in and tracking of energy and nutrient intake over 20 years in a Dutch cohort of men and women between 13 and 33 years of age: the Amsterdam growth and health longitudinal study. Br J Nutr 2001;85:375-385.
30 Lake AA, Adamson AJ, Craigie AM, Rugg-Gunn AJ, Mathers JC: Tracking of dietary intake and predicting dietary change from early adolescence to adulthood: the ASH30 Study. Obes Facts 2009; 2(3):157-165.

31 Malina RM: Physical activity and fitness: pathways from childhood to adulthood. Am J Hum Biol 2001;13:162-172.

32 Parsons TJ, Power C, Manor O: Longitudinal physical activity and diet patterns in the 1958 British birth cohort. Med Sci Sports Exerc 2006;38:547-554.

33 Twisk JW, Kemper HC, Van Mechelen W, Post GB: Tracking of risk factors for coronary heart disease over a 14-year period: a comparison between lifestyle and biologic risk factors with data from the Amsterdam Growth and Health Study. Am J Epidemiol 1997;145:888-898.

34 Loos RJ, Bouchard C: Obesity - is it a genetic disorder? J Intern Med 2003;254:401-425.

35 Rose KM, Newman B, Mayer-Davis EJ, Selby JV: Genetic and behavioral determinants of waist-hip ratio and waist circumference in women twins. Obes Res 1998;6:383-392.

36 Casey VA, Dwyer JT, Berkey CS, Bailey SM, Coleman KA, Valadian I: The distribution of body fat from childhood to adulthood in a longitudinal study population. Ann Hum Biol 1994;21:39-55.

37 Rolland-Cachera MF, Bellisle F, Deheeger M, Pequignot F, Sempe M: Influence of body fat distribution during childhood on body fat distribution in adulthood: a two-decade follow-up study. Int J Obes 1990;14:473-481.

38 van Lenthe FJ, Kemper HC, van Mechelen W, Twisk JW: Development and tracking of central patterns of subcutaneous fat in adolescence and adulthood: the Amsterdam Growth and Health Study. Int J Epidemiol 1996;25:1162-1171.

39 Han TS, van Leer EM, Seidell JC, Lean ME: Waist circumference action levels in the identification of cardiovascular risk factors: prevalence study in a random sample. BMJ 1995;311:1401-1405.

40 Molarius A, Seidell JC: Selection of anthropometric indicators for classification of abdominal fatness - a critical review. Int J Obes 1998:22:719-727.

41 Summerbell CD, Ashton V, Campbell KJ, Edmunds L, Kelly S, Waters E: Interventions for treating obesity in children. Cochrane Database Syst Rev 2005: CD001871.

42 Campbell K, Waters E, O’Meara S, Kelly S, Summerbell $\mathrm{C}$ : Interventions for preventing obesity in children. Cochrane Database Syst Rev 2005:CD001871.

43 Widhalm K, Fussenegger D: Actions and programs of European countries to combat obesity in children and adolescents: a survey. Int J Obes 2005;29: 130-135.

44 Butland B, Jebb S, Kopelman P, McPherson K, Thomas S, Mardell J, Parry V: Tackling obesities: future choices - project report 2007. www.foresight. gov.uk/Obesity/17.pdf. 